\title{
BMJ Open Statistical tools used for analyses of frequent users of emergency department: a scoping review
}

\author{
Yohann Chiu, ${ }^{\oplus 1}$ François Racine-Hemmings, ${ }^{1}$ Isabelle Dufour, ${ }^{1}$ Alain Vanasse, ${ }^{1}$ \\ Maud-Christine Chouinard, ${ }^{2}$ Mathieu Bisson, ${ }^{1}$ Catherine Hudon ${ }^{1}$
}

To cite: Chiu Y, RacineHemmings F, Dufour I, et al. Statistical tools used for analyses of frequent users of emergency department: a scoping review. BMJ Open 2019;9:e027750. doi:10.1136/ bmjopen-2018-027750

- Prepublication history and additional material for this paper are available online. To view these files, please visit the journal online (http://dx.doi. org/10.1136/bmjopen-2018027750).

Received 6 November 2018

Revised 22 March 2019

Accepted 18 April 2019
Check for updates

(c) Author(s) (or their employer(s)) 2019. Re-use permitted under CC BY-NC. No commercial re-use. See rights and permissions. Published by BMJ.

${ }^{1}$ Department of Family Medicine and Emergency Medicine, Université de Sherbrooke, Sherbrooke, Quebec, Canada ${ }^{2}$ Department of Health Sciences, Université du Québec à Chicoutimi, Chicoutimi, Quebec, Canada

Correspondence to

Yohann Chiu;

yohann.chiu@usherbrooke.ca

\section{ABSTRACT}

Objective Frequent users represent a small proportion of emergency department users, but they account for a disproportionately large number of visits. Their use of emergency departments is often considered suboptimal. It would be more efficient to identify and treat those patients earlier in their health problem trajectory. It is therefore essential to describe their characteristics and to predict their emergency department use. In order to do so, adequate statistical tools are needed. The objective of this study was to determine the statistical tools used in identifying variables associated with frequent use or predicting the risk of becoming a frequent user.

Methods We performed a scoping review following an established 5-stage methodological framework. We searched PubMed, Scopus and CINAHL databases in February 2019 using search strategies defined with the help of an information specialist. Out of 4534 potential abstracts, we selected 114 articles based on defined criteria and presented in a content analysis.

Results We identified four classes of statistical tools. Regression models were found to be the most common practice, followed by hypothesis testing. The logistic regression was found to be the most used statistical tool, followed by $\chi 2$ test and t-test of associations between variables. Other tools were marginally used.

Conclusions This scoping review lists common statistical tools used for analysing frequent users in emergency departments. It highlights the fact that some are well established while others are much less so. More research is needed to apply appropriate techniques to health data or to diversify statistical point of views.

\section{BACKGROUND}

Emergency department (ED) 'frequent users' are a sub-group of ED users that make repeated, multiple visits during a given amount of time. Though there is no consensus about definition for frequent users, thresholds in the literature range from two to more than $10 \mathrm{ED}$ visits per year, ${ }^{12}$ while the most common one is more than four ED visits per year. ${ }^{12}$ Frequent users represent a small proportion of ED users but account for a large number of visits. ${ }^{3-5}$ They often display complex characteristics such as low

\section{Strengths and limitations of this study}

First overview of statistical tools used in frequent users analysis.

- Follows a well-defined methodological framework in an extensive body of literature.

- Quality assessment is not performed in a scoping review.

- Studies in other languages than English or French might have been missed.

socioeconomic status combined with physical and mental health issues. ${ }^{6}$ As such, their ED use is considered suboptimal, ${ }^{7}$ as the best strategy would be to identify those patients at an earlier stage in their health problem trajectory, in order to treat them more efficiently. ${ }^{8}$ Furthermore, frequent users' visits may lead to overcrowding in EDs and decreased quality of care. ${ }^{2}$ Identifying factors that best describe those users and predict their ED use is therefore an essential task to improve ED care as well as frequent users' health problems. Adequate statistical tools are needed to that end. Although they are numerous, no literature review has been published yet about statistical tools used for analysing ED frequent users. Therefore, the aim of our study was to draw up a list of statistical tools used in identifying variables associated with frequent use or predicting the risk of becoming a frequent user.

\section{METHODS}

In order to list the statistical tools used in describing variables associated with and prediction of frequent ED use, we conducted a scoping review. We followed the 5-stage methodology of Arksey and $\mathrm{O}^{\prime}$ Malley ${ }^{9}$ adapted by Levac et al. ${ }^{10}$ The methodological framework of a scoping review allows "mapping rapidly the key concepts underpinning a research area and the main sources and types of 
evidence available, ${ }^{11}$ thus allowing us to identify gaps in the literature and future research opportunities.

\section{Stage 1: Identifying the research question}

We defined our research question as follows: What statistical tools are used in the identification of variables associated with frequent ED users and in their prediction?

\section{Stage 2: Identifying relevant studies}

We searched PubMed, CINAHL and Scopus databases in February 2019, using search strategies developed with the help of an information specialist (see the online supplementary appendix for the complete search strategy). Keywords included variants of 'frequent users', 'emergency departments' and 'statistical tools'.

There were no restriction regarding the population age or sex, health conditions, study period or country.

\section{Stage 3: Study selection}

Articles written in French or in English were included using the following criteria:

- The study must focus on frequent users of EDs (studies focusing on re-visits or on frequent visits other than in EDs were excluded).

- The study must have an explicit definition of frequent users, such as four visits in 1 year (reviews were excluded).

- The study must use at least one statistical tool that is classified as inferential (not descriptive, as defined by The Cambridge Dictionary of Statistics ${ }^{12}$ ), such as hypothesis tests, regression models, decision trees or others.

- The study's objectives must include identifying variables associated with frequent use or predicting the risk of becoming a frequent user.

We collected 4534 potential abstracts (figure 1). Of those, 32 were duplicates and 4344 were excluded by an investigator (YC) after reading the title and the abstract. At this stage, studies were discarded if it was explicit from the title and the abstract that they were unfit for the scoping review (for instance studies about frequent use of inpatient services, systematic reviews, etc). In case of uncertainty, studies were kept for complete reading. Then, YC and FRH or ID independently evaluated the remaining 158 full text articles, of which 109 matched the above criteria. A third evaluator was consulted in case of discrepancy. Reasons for exclusion were: not in French or English (1), duplicate (3), systematic review (4), no inferential statistics (5), no explicit definition of frequent users (5), focus not on ED (14), no description or prediction of frequent users (17). A reference search among the references of the 109 included articles yielded five relevant articles. Thus, 114 articles were included in this study, of which YC, ID and MB examined the full texts.

\section{Stage 4: Charting the data}

YC, MB and ID independently extracted the corresponding data. Reported characteristics were the first (two) author(s), the publication year, the study

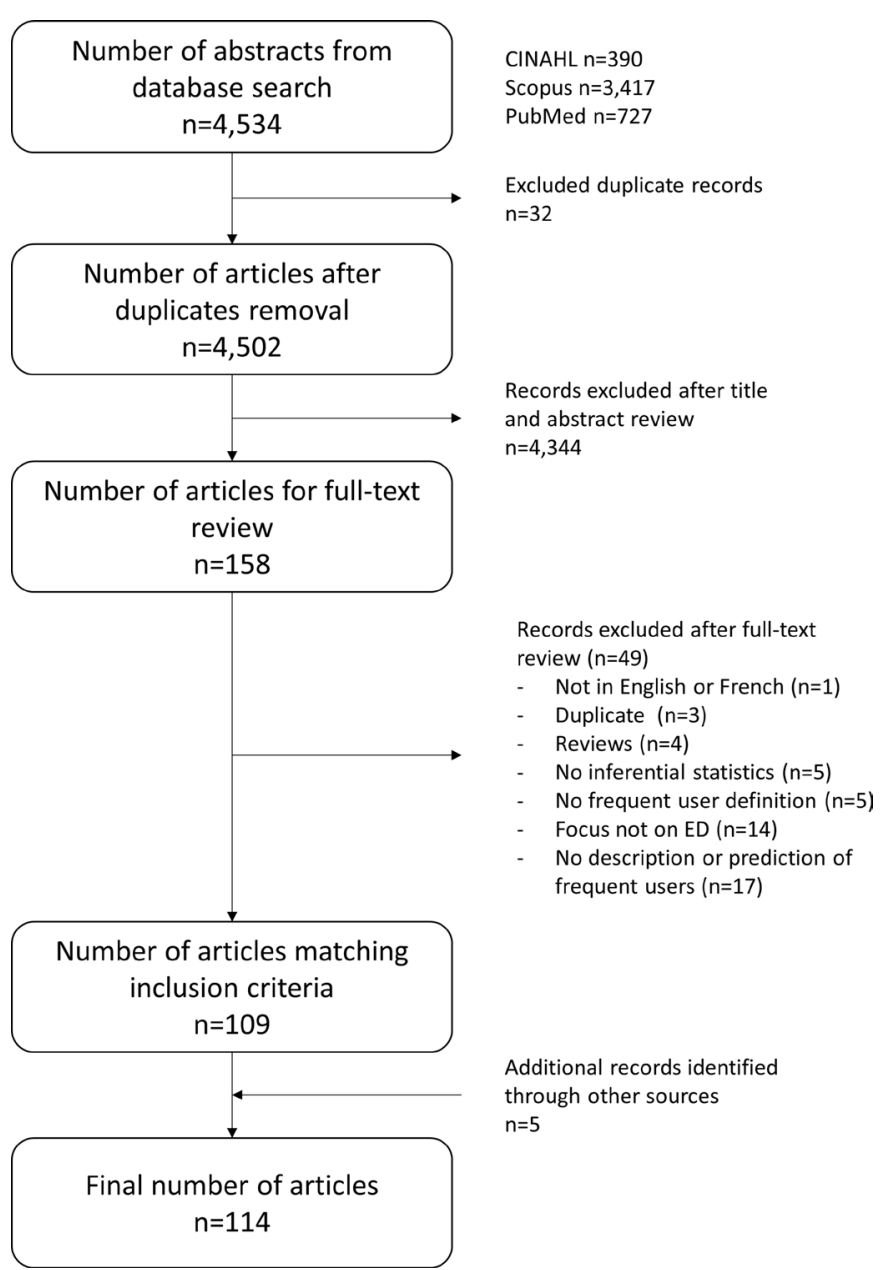

Figure 1 Preferred Reporting Items for Systematic Reviews and Meta-Analyses flow diagram. ED, emergency department.

location, the population, the frequent users' definition, the objectives, the sample size and the statistical tools used concerning the research question.

\section{Stage 5: Collating, summarising and reporting the results} The results are reported via a content analysis. ${ }^{13}$

\section{Patient and public involvement}

Patients or public were not involved in this study.

\section{RESULTS}

The studies' main characteristics are presented in table 1 . Out of 114 studies, 65 were conducted in the USA, 17 in Canada and 8 in Australia (figure 2). The various statistical tools were classified into four main categories: regression, hypothesis testing, machine learning and other tools.

\section{Regression}

Regression tools consist of a set of processes aimed at quantifying the relationships between a dependent variable and other explanatory variables. ${ }^{14}$ They are useful for description and prediction. Some regression models may be regularised, which in this case means avoiding 

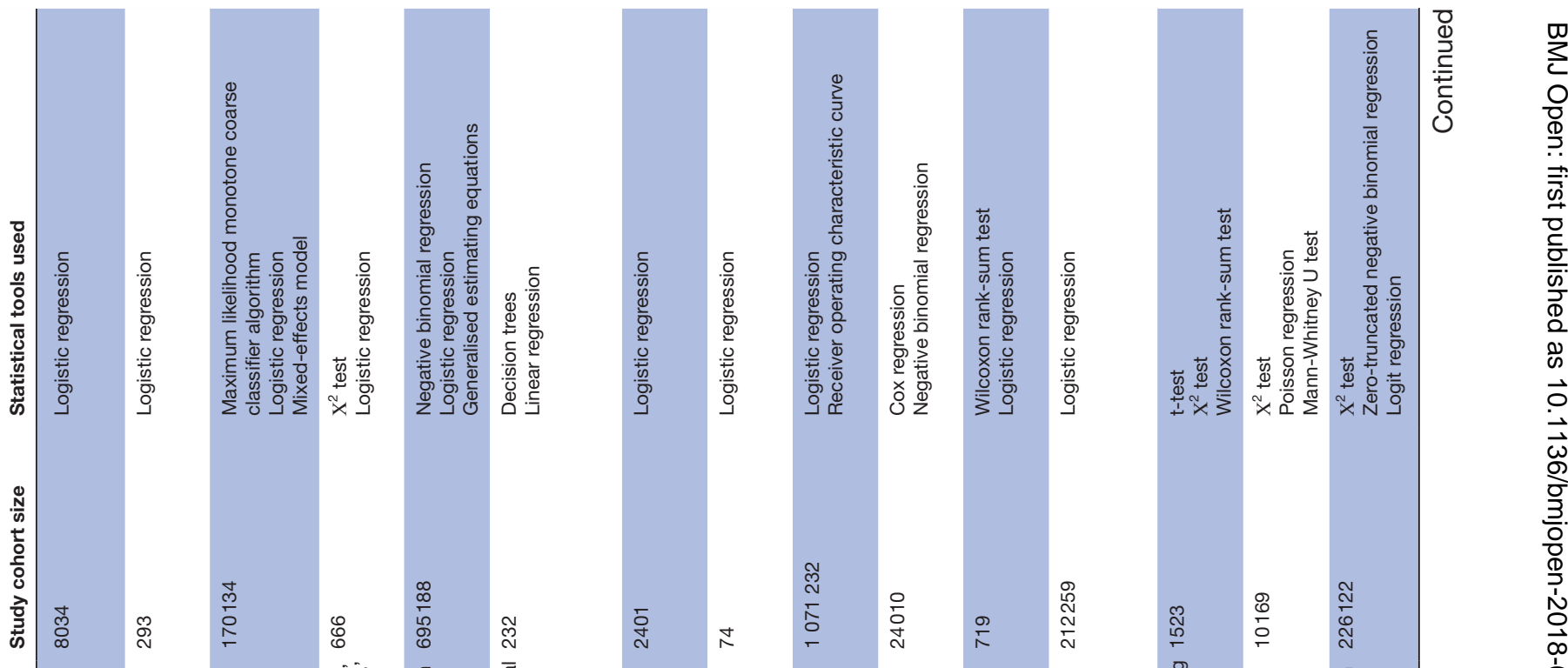

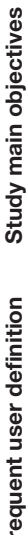

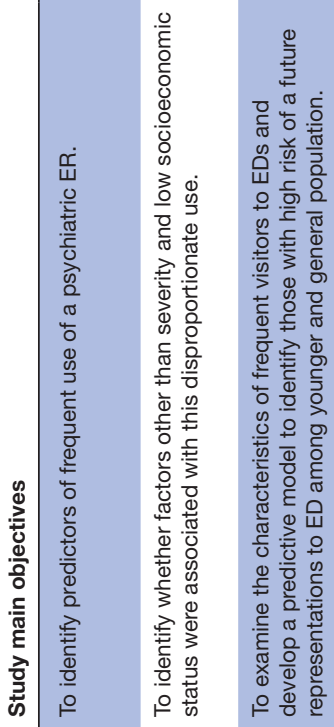

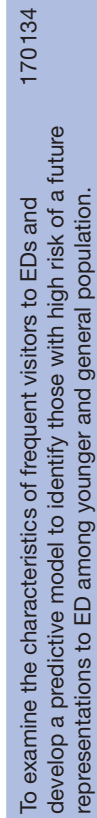
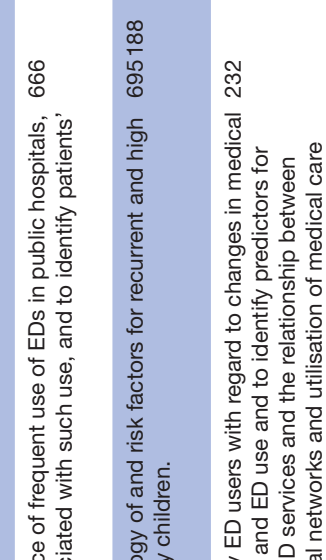

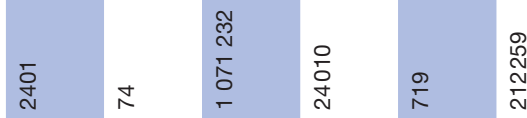
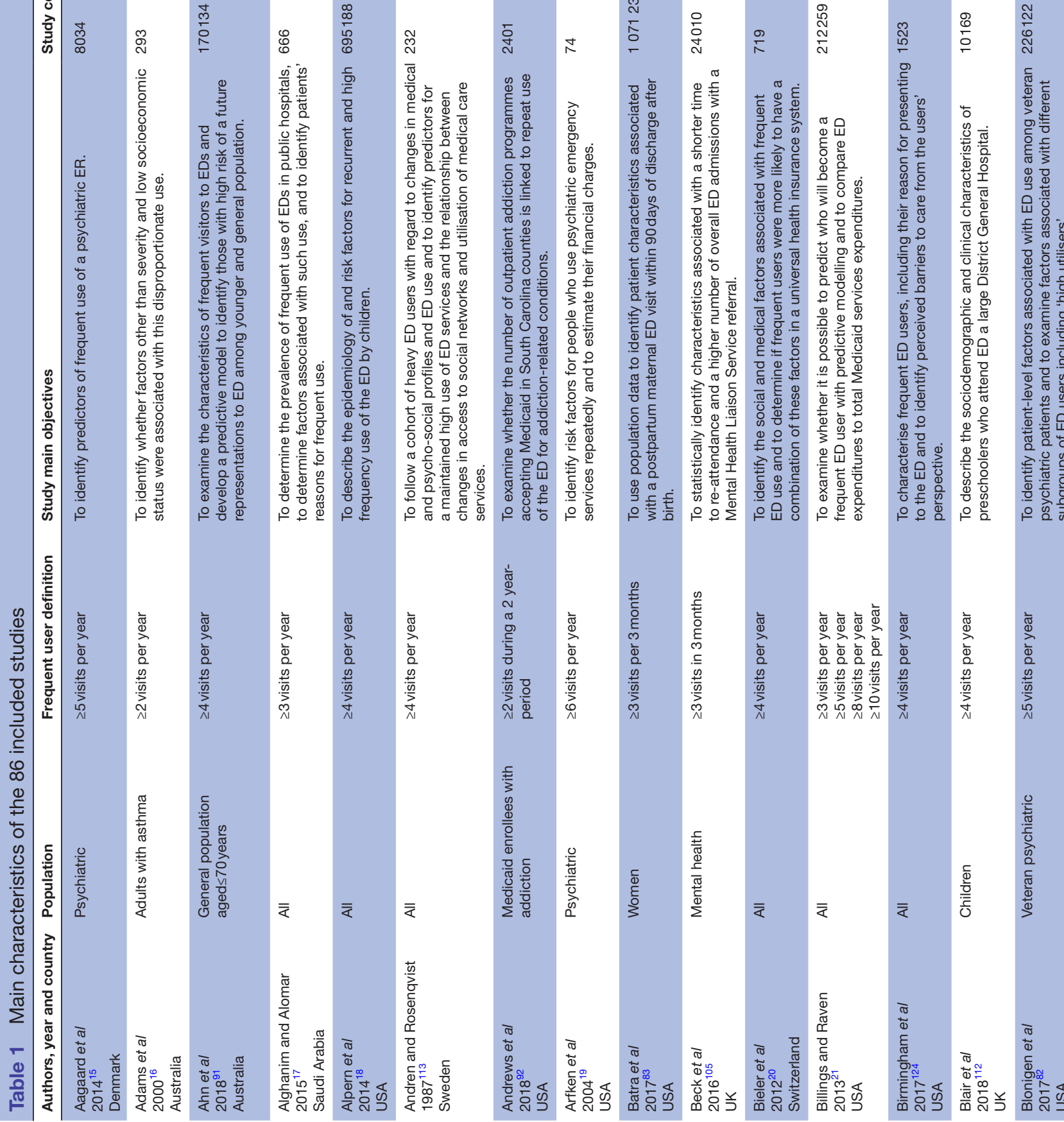


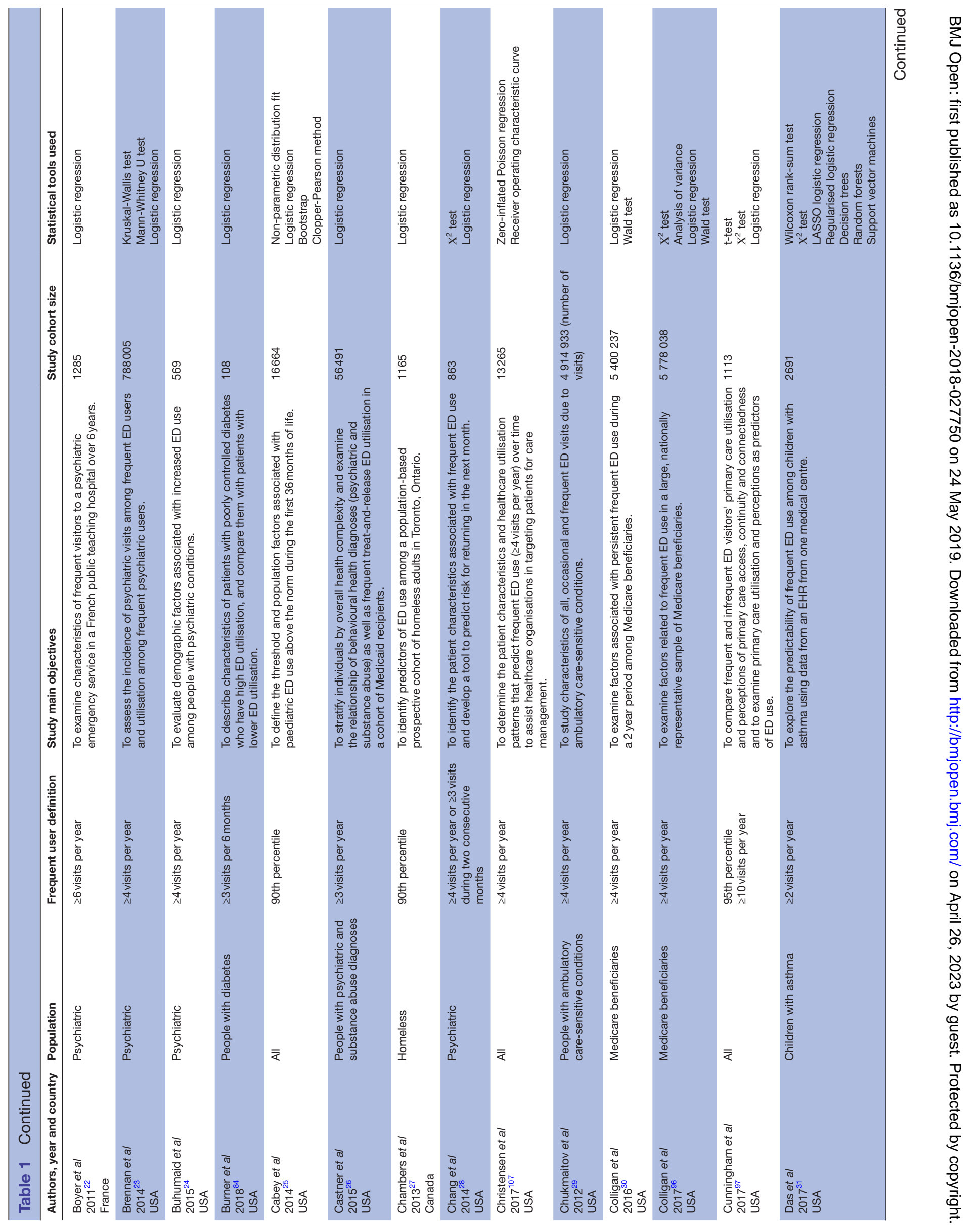




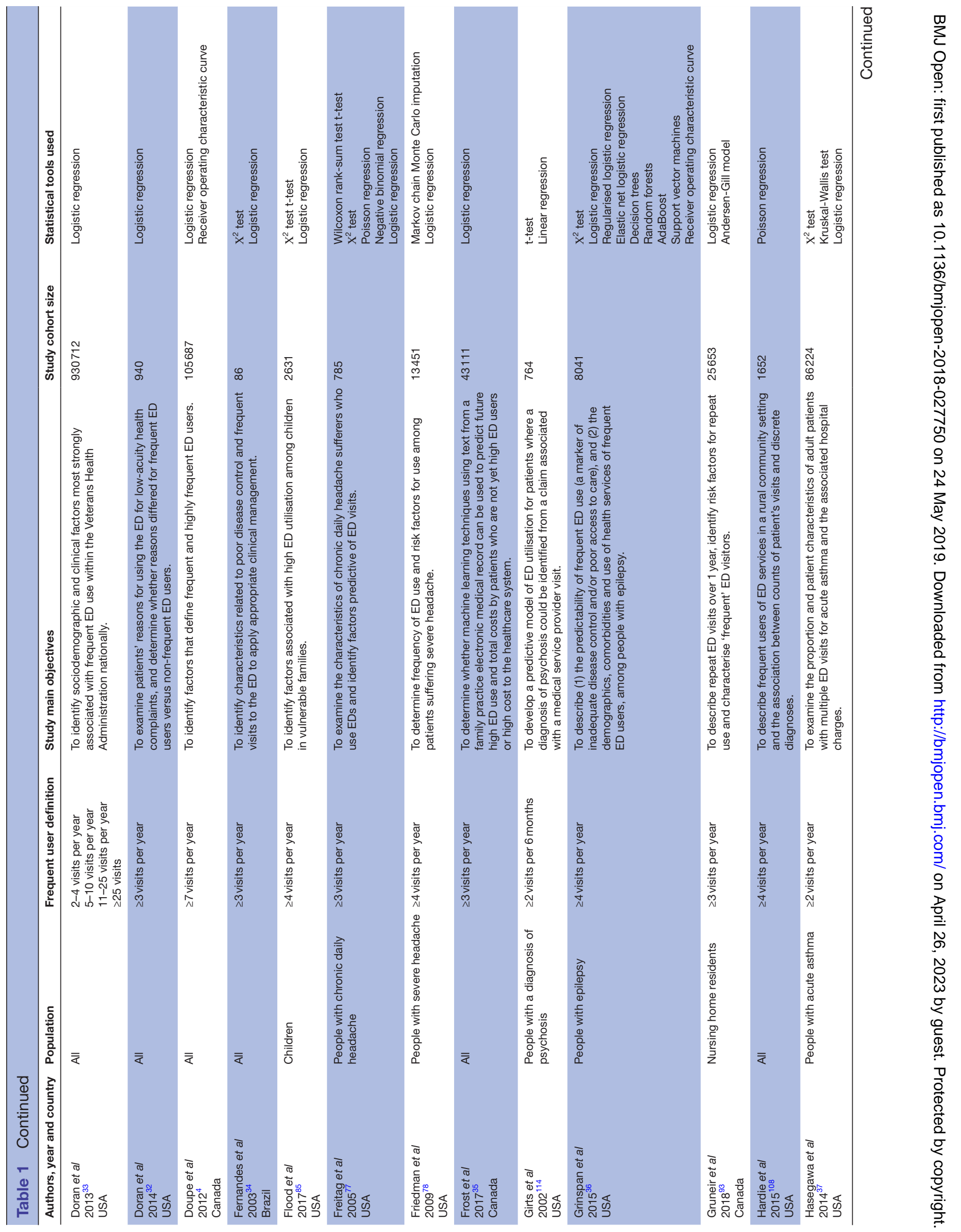




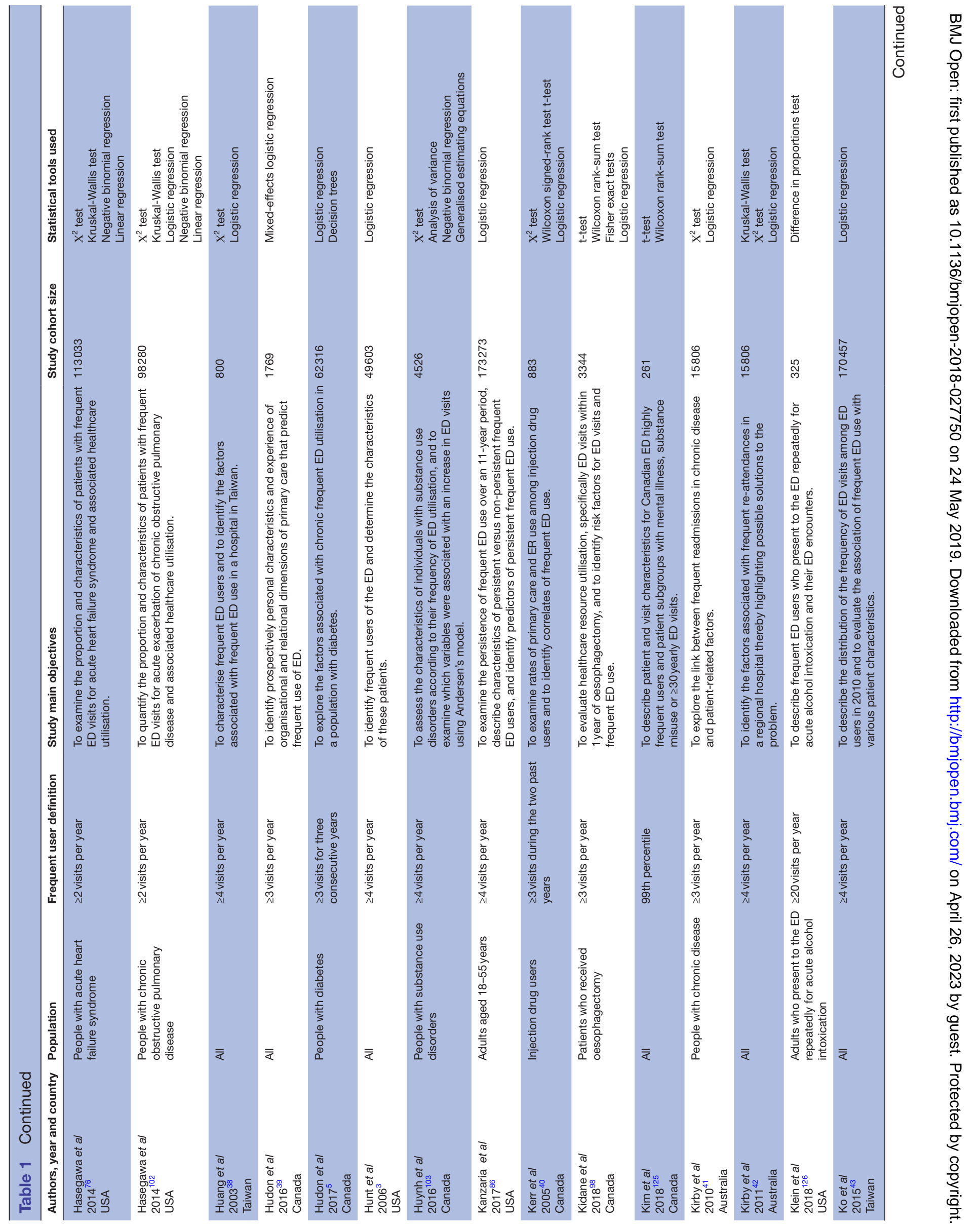




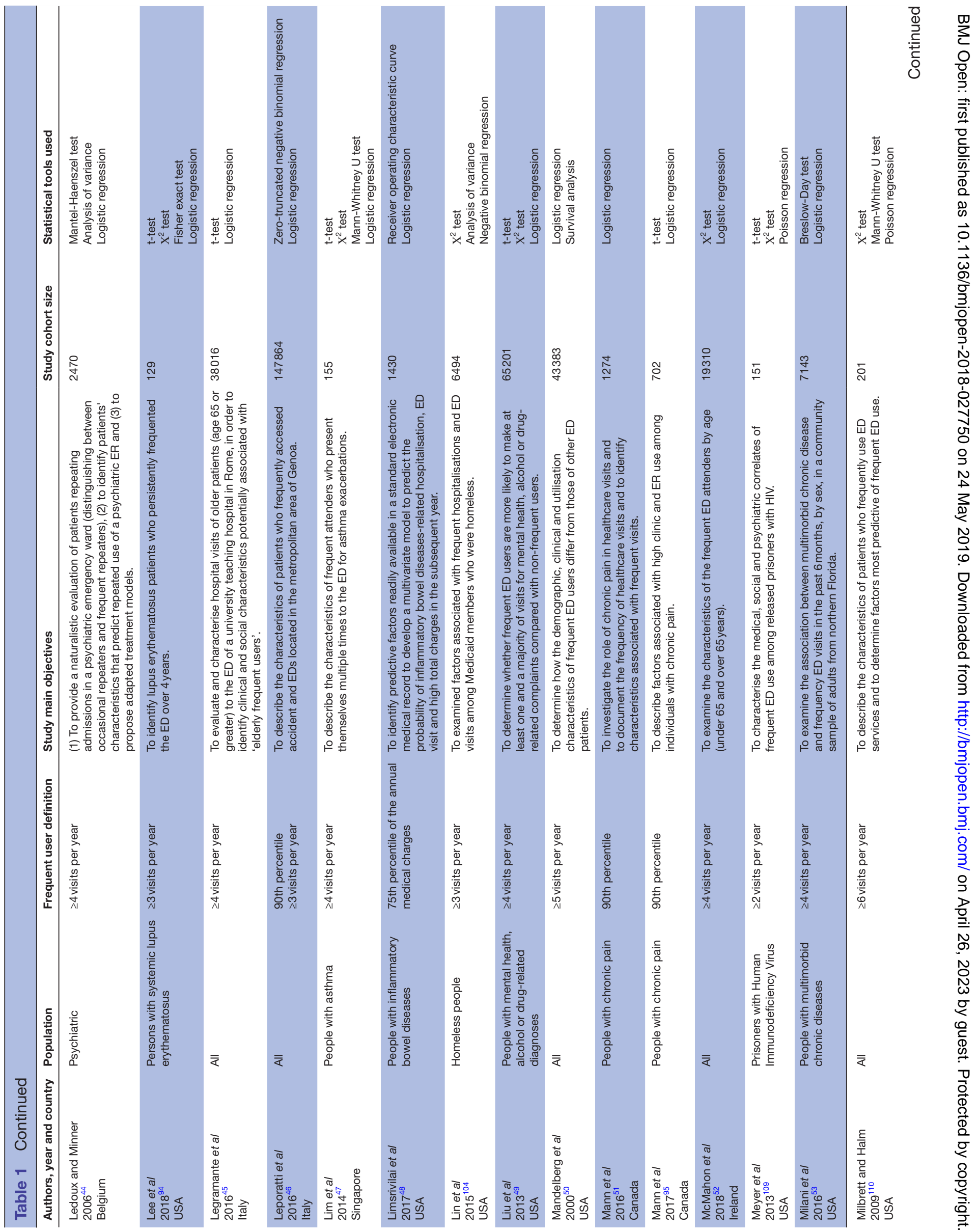




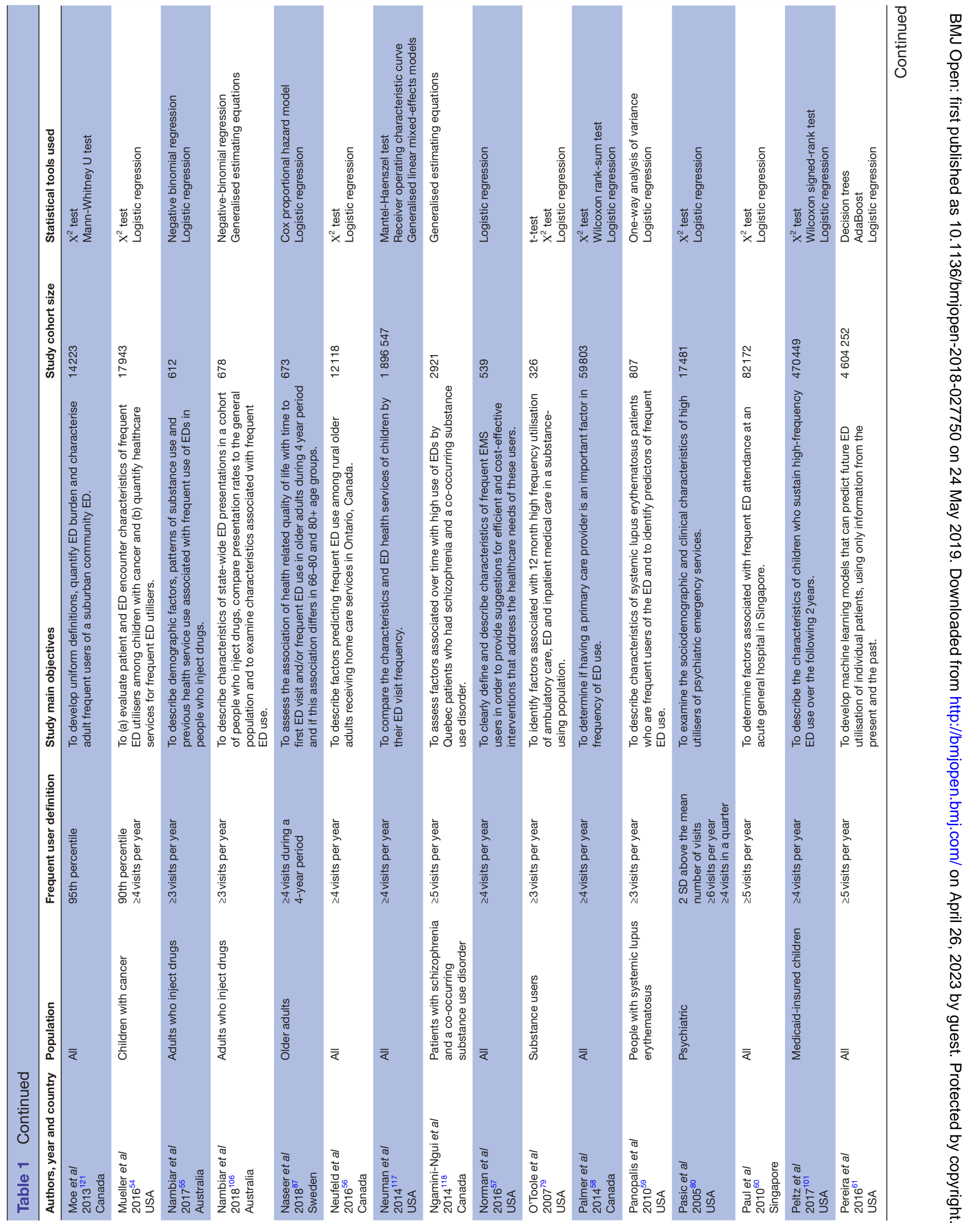




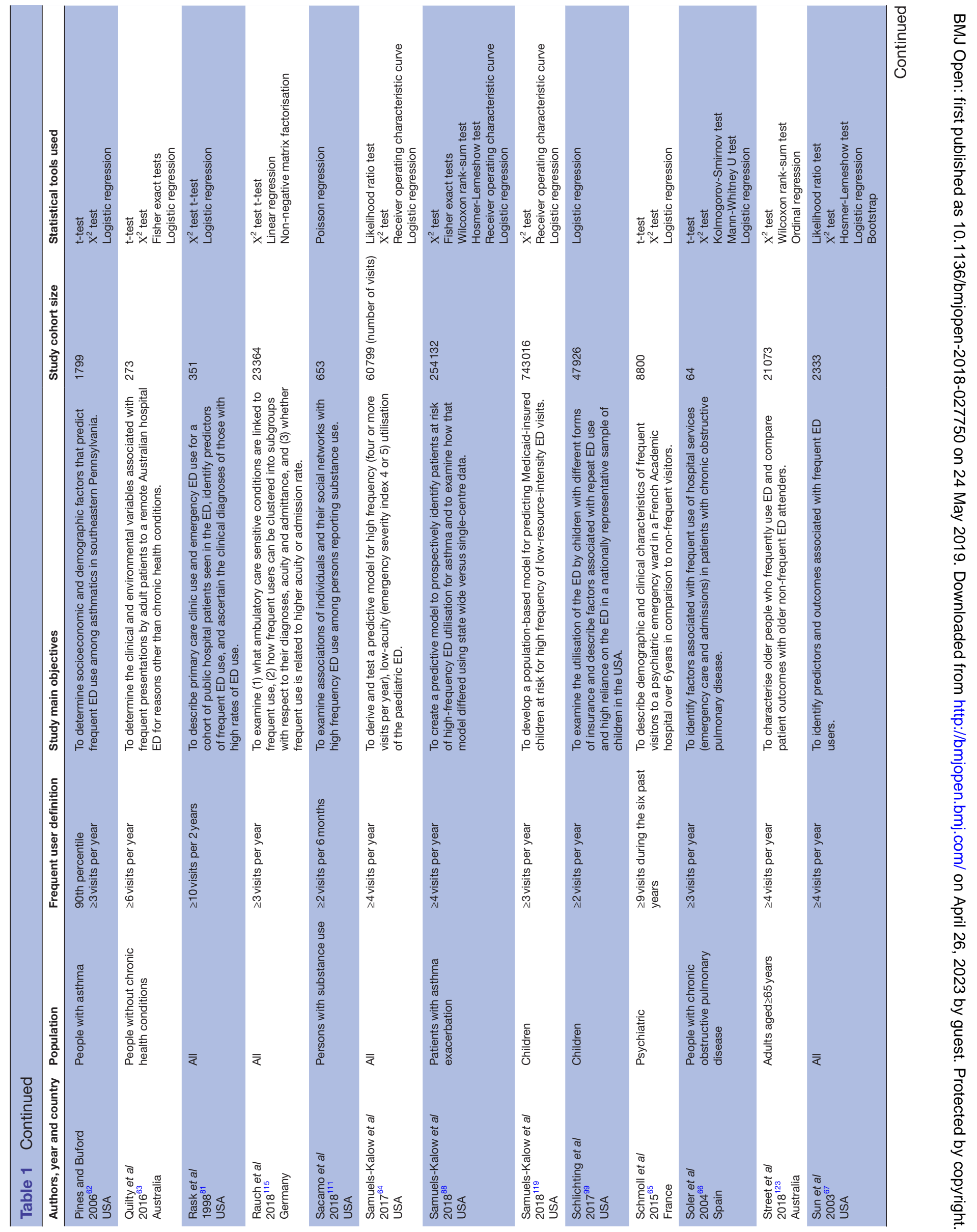




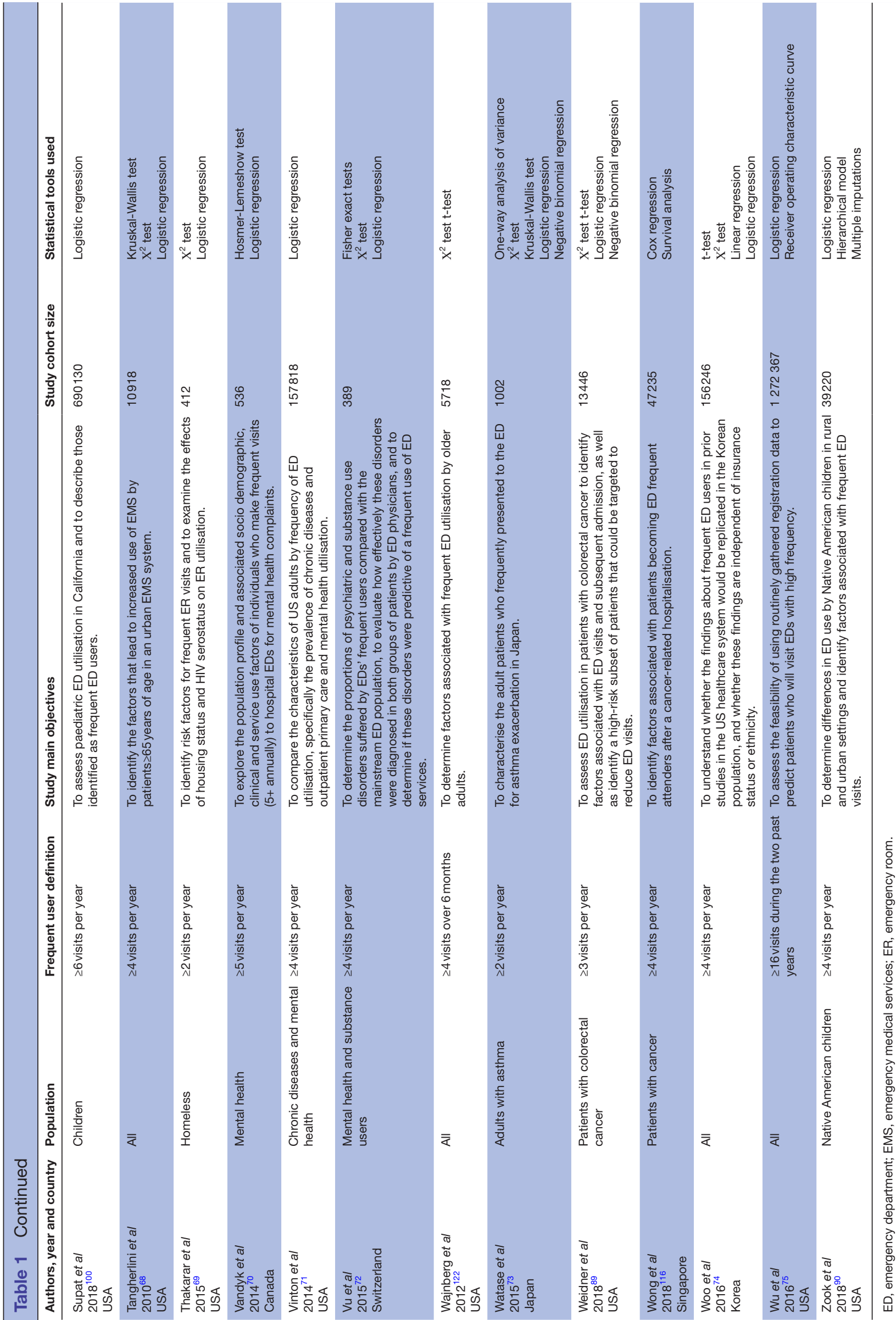

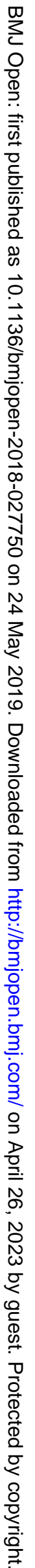




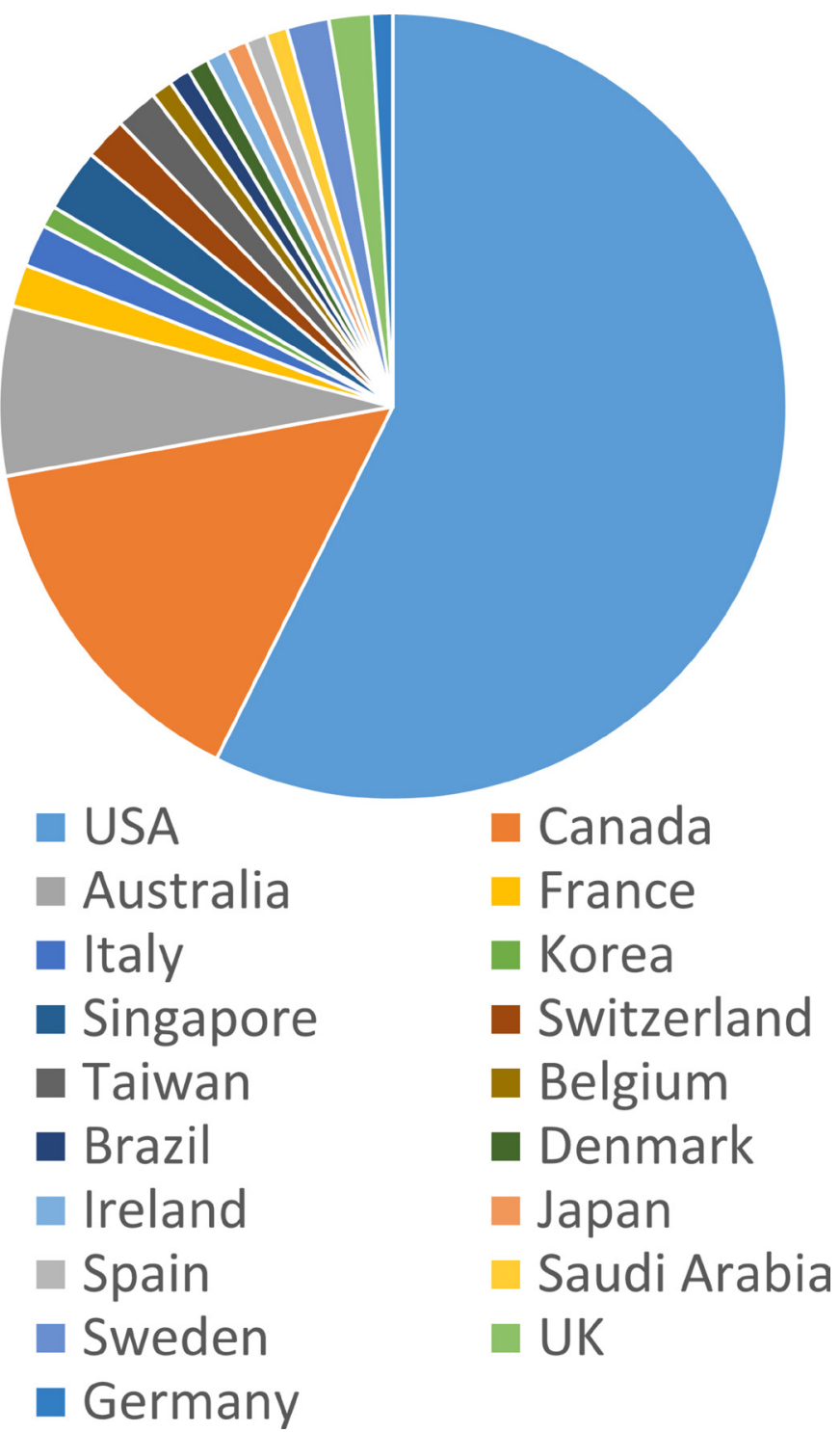

Figure 2 Number of studies by country.

overfitting with too many explanatory variables, or zero-truncated, which means that the model is not allowed to take null values.

Out of the four categories (regression, hypothesis testing, machine learning and other tools), the most reported tool was the logistic regression (90 studies, ${ }^{3-5} 15-101$ two of which are regularised by LASSO or elastic net techniques), followed by the binomial regression (13 studies, ${ }^{1846} 557376778289$ 102-106 2 of which are zero-truncated). To a lesser extent, the Poisson regression (seven studies, ${ }^{77} 107-112$ one of which is zero-truncated), the linear regression (six studies ${ }^{74} 766_{102} 113-115$ ), the analysis of variance (six studies ${ }^{44} 597396103104$ ), the Cox regression (four studies ${ }^{8793105116}$ ) and hierarchical models $\left(\right.$ one study ${ }^{90}$ ) were also used. In those studies, the results are often associated with ORs. The mixed-effects models were mentioned three times. ${ }^{39} 91117$ Regression parameters were estimated by generalised estimating equations in four studies ${ }^{18} 103106118$ while parameter confidence intervals were estimated by the bootstrap procedure (two studies ${ }^{25}$ ) ) and the Clopper-Pearson method (one study ${ }^{25}$ ). The receiver operating characteristic curve, or equivalently the sensitivity, specificity or area under the curve ('c-statistic'), was computed in 10 studies. $^{4364864758388107117119}$ Finally, two studies performed imputation to account for missing data (Markov chain Monte Carlo and multiple imputations $\left.{ }^{78}{ }^{90}\right)$.

\section{Hypothesis testing}

Statistical tests aim at testing a specific hypothesis about data and rely on probability distributions. ${ }^{120}$ In the selected studies, the tests aimed mainly at comparing two samples (frequent users and non-frequent users).

The most common statistical tests were the $\chi^{2}$ test (53 studies 17283134 36-38 40-42 47495254565860 62-69 72-74 7677 79-82 85 8889949697 101-104109110112115119 121-124) and the t-test (24 studies 404547496263656674777981858994959798109114115122 124125 ) which measured association between variables or goodness-of-fit. As an alternative to the $\chi^{2}$ test for association, five studies used the Fisher exact test. ${ }^{63} 729498119$ Sample mean differences were assessed by 23 studies with the Mann-Whitney U test (also called the Wilcoxon rank-sum test ${ }^{2023314758667798110119121123-125}$ ), its variant for dependent samples the Wilcoxon signed rank test, ${ }^{40} 101$ or the Kruskal-Wallis test. ${ }^{23} 3742687376102$ The difference in proportions test, ${ }^{126}$ Mantel-Haenszel test (test for differences in contingency tables, two studies ${ }^{44}{ }^{117}$ ), the likelihood ratio test (significance test for nested models, two studies ${ }^{64}{ }^{67}$ ), the Hosmer-Lemeshow test (goodness-of-fit for logistic regression, two studies ${ }^{67} 70$ ), the Wald test (significance test for regression coefficients, two studies ${ }^{306}$ ) and the Breslow-Day test (test for homogeneity in contingency tables $\mathrm{OR}^{53}$ ) were also used to a lesser degree. Finally, one study checked the assumption of normality with the Kolmogorov-Smirnov test. ${ }^{66}$

\section{Machine learning}

Machine learning tools are a set of algorithms that can learn and adapt to data in order to classify or predict, for instance. ${ }^{127}$ In the selected studies, the machine learning tools aimed mainly at classifying users (frequent vs non-frequent).

Two studies used random forests ${ }^{31}{ }^{36}$ along with support vector machines. Decision trees, which include classification and regression trees, were implemented by five studies. ${ }^{5} 313661113$ Adaptive boosting, or AdaBoost, is a meta-algorithm that combines with other algorithms and helps for better performances. It was computed in two studies. ${ }^{361}$

\section{Other tools}

Two studies used survival analysis, ${ }^{50} 116$ while another one fitted a non-parametric distribution to their data. ${ }^{25}$ Finally, maximum likelihood monotone coarse classifier algorithm was used as a binning method ${ }^{91}$ and non-negative matrix factorisation as a clustering technique. ${ }^{115}$ 


\section{DISCUSSION}

The most exploited statistical tools arguably came from regression analysis. This may be because regression is well established in medical statistics or also because it is the most natural tool when trying to find significant variables to explain a dependent variable (in this case, to be a frequent user). Moreover, it allows predicting easily the risk of a new user becoming a frequent user, depending on its covariates. Other tools from hypothesis testing or machine learning also proved to be popular, although to a much lesser extent. Combining these statistical techniques may help in discovering significant and complementary patterns, compared with using tools from one class only. In our scoping review, two studies mixed statistical tools from regression, hypothesis testing and machine learning. ${ }^{3136}$ In those studies, the author evaluated various performance criteria. While logistic regression performed well, other techniques such as random forests or LASSO regression were also competitive. Besides the fact that logistic regression can display modest performances, ${ }^{128}$ random forests and LASSO regression can complete logistic regression. The first technique can be used to assess the importance of each independent variable in the model, while the second technique can be useful for automatic selection of features. Likewise, using a variety of statistical tools can help complete or confirm results obtained with established methodologies. Different tools from one class can also be mixed in order to achieve different stages of the analysis (for instance, different types of regression ${ }^{82}$ ).

The analysis of frequent ED users could benefit from using more machine learning techniques. Those were found to be not as common as regression or hypothesis testing, although they are especially appropriate when dealing with classification, prediction or big data. Tools such as support vector machines (which were used by two studies in this scoping review ${ }^{31}$ ), artificial neural networks or Bayesian networks are common classifiers and predictors in the artificial intelligence community. ${ }^{129}$ They are popular for instance in cancer diagnostic and prognosis, which strongly rely on classification and prediction. ${ }^{130-132}$ In particular, support vector machines, decision trees or self-organising maps can deal with binary outcomes, which is usually the case for frequent use outcomes. They usually require large datasets in order to overcome overfitting, but this is becoming less and less of an issue in health sciences. ${ }^{133}$ Nevertheless, machine learning tools often use a black box approach as there are many intermediary steps leading to the final solution. While each step usually consists of simple arithmetic operations, their multiple interactions can be more difficult to interpret. In spite of this opacity, they still display good performances in classifying and predicting. In some cases, they may be more accurate than the widely used logistic regression. ${ }^{134}$ Those methods would thus turn out to be less useful in data exploration. ${ }^{135}$ Machine learning tools are getting popular in other fields in health sciences, such as critical care, ${ }^{136}$ cardiology ${ }^{137}$ or emergency medicine. ${ }^{138}$
The authors state that their fields would benefit from this growing popularity, though results need to be analysed and interpreted in collaboration with clinicians.

Other tools exist that may also be suitable for describing the associated variables or the prediction of frequent ED users but were not reported in the literature. Among those, principal component analysis (PCA) is a dimensional reduction and visualisation technique, sometimes used with cluster or discriminant analysis. ${ }^{139}$ Based on all the original explanatory variables, PCA constructs new ones by summing and weighing them differently. More weight is given to relevant variables so that those latter become dominant in the new constructions while still including all variables. For instance, Burgel et $a l^{140}$ built chronic obstructive pulmonary disease clinical phenotypes by constructing new relevant variables with PCA and by grouping similar subjects in this new space with cluster analysis. ${ }^{140}$ Moreover, PCA has already been used for the construction of questionnaires and diagnosis tools in a medical context, ${ }^{141142}$ both of which can prove useful in the identification of frequent users.

As mentioned, regression techniques were common in the selected studies. Yet, quantile regression $(\mathrm{QR})^{143}$ was not mentioned. QR is a generalisation of mean regression in the sense that its focus is not only the mean of the dependent variable distribution (such as in classical linear regression) but any quantile of it. $\mathrm{QR}$ thus represents an alternative to define frequent users by the high quantiles of ED visit distribution (eg, the 90th quantile). Eight studies 25274648515462121 defined frequent users with quantiles, but they did not use QR. QR would allow for finer investigations in the different quantiles of $\mathrm{ED}$ users in relationship to the explanatory variables. For instance, the association between age and the number of ED visits may be significantly different across the 10th (low users) and 90th (frequent users) quantiles. Such a heterogeneous association would be uncovered by $\mathrm{QR}$, while usually unseen with a classical mean regression. Ding et $a l^{144}$ used QR to characterise waiting room and treatment times in EDs. ${ }^{144}$ They explored the lowest, median and highest of those times and highlighted predictors that were significant only in particular quantiles. Usually, $\mathrm{QR}$ requires a continuous dependent variable as opposed to a logistic regression, though it is possible to combine these two regressions. ${ }^{145}$ Furthermore, defining frequent users by quantiles would allow for better comparison between studies as there is no common definition for frequent users.

\section{Strengths and limitations}

To the best of our knowledge, this scoping review is the first to list statistical tools that are used in the identification of variables associated with frequent ED use and the prediction of frequent users. Besides, it was conducted following a well-defined methodological framework. The search strategies were designed with an information specialist in three different databases. Two independent evaluators selected the articles and extracted the data 
while a third independent evaluator settled disagreements, ensuring that all included studies were relevant. One limitation of our study is that quality assessment is not performed in a scoping review. However, this should not alter the results, since the aim was to list which statistical tools have been applied in the literature. Moreover, the majority of articles were in English which may introduce a selection bias (for instance, one excluded article was in Spanish). More than half of the reviewed studies were indeed conducted in the USA, making the results difficult to compare to other countries.

\section{CONCLUSIONS}

Frequent ED users represent a complex issue, and their analysis require adequate statistical tools. In this context, this scoping review shows that some tools are well established, such as logistic regression and $\chi^{2}$ test, while others such as support vector machines are less so, though they would deserve to get more attention. It also outlines some research opportunities with other tools not yet explored.

Acknowledgements We would like to thank information specialist Josée Toulouse for her help in defining the search strategies and Tina Wey $(\mathrm{PhD})$ for revising the text.

Contributors $\mathrm{YC}$ and $\mathrm{CH}$ designed the study with $\mathrm{FR}-\mathrm{H}, \mathrm{ID}$ and $\mathrm{AV}$. YC, ID, $\mathrm{CH}$ and $\mathrm{MB}$ collected and analysed the data. $\mathrm{YC}$ and $\mathrm{CH}$ wrote the first draft of the manuscript. FR-H, ID, AV, M-CC and MB contributed to the writing of the manuscript. All authors read and approved the final manuscript.

Funding This work was financed by grants from the Fonds de recherche du Québec - Santé and the Centre de recherche du Centre hospitalier universitaire de Sherbrooke. The funders had no role in study design, data collection and analysis, decision to publish, or preparation of the manuscript.

Competing interests None declared.

Patient consent for publication Not required.

Provenance and peer review Not commissioned; externally peer reviewed.

Data sharing statement There are no unpublished additional data from the study.

Open access This is an open access article distributed in accordance with the Creative Commons Attribution Non Commercial (CC BY-NC 4.0) license, which permits others to distribute, remix, adapt, build upon this work non-commercially, and license their derivative works on different terms, provided the original work is properly cited, appropriate credit is given, any changes made indicated, and the use is non-commercial. See: http://creativecommons.org/licenses/by-nc/4.0/.

\section{REFERENCES}

1. Kumar GS, Klein R. Effectiveness of case management strategies in reducing emergency department visits in frequent user patient populations: a systematic review. J Emerg Med 2013;44:717-29.

2. LaCalle E, Rabin E. Frequent users of emergency departments: the myths, the data, and the policy implications. Ann Emerg Med 2010;56:42-8.

3. Hunt KA, Weber EJ, Showstack JA, et al. Characteristics of frequent users of emergency departments. Ann Emerg Med 2006;48:1-8.

4. Doupe MB, Palatnick W, Day S, et al. Frequent users of emergency departments: developing standard definitions and defining prominent risk factors. Ann Emerg Med 2012;60:24-32.

5. Hudon C, Courteau J, Krieg C, et al. Factors associated with chronic frequent emergency department utilization in a population with diabetes living in metropolitan areas: a population-based retrospective cohort study. BMC Health Serv Res 2017;17:525.

6. Krieg C, Hudon C, Chouinard MC, et al. Individual predictors of frequent emergency department use: a scoping review. BMC Health Serv Res 2016;16:594.
7. Ruger JP, Richter CJ, Spitznagel EL, et al. Analysis of costs, length of stay, and utilization of emergency department services by frequent users: implications for health policy. Acad Emerg Med 2004;11:1311-7.

8. Bodenheimer T, Berry-Millett R. Care management of patients with complex health care needs. Policy 2009;1:6.

9. Arksey H, O'Malley L. Scoping studies: towards a methodological framework. Int J Soc Res Methodol 2005;8:19-32.

10. Levac D, Colquhoun H, O'Brien KK. Scoping studies: advancing the methodology. Implement Sci 2010;5:69.

11. Mays N, Roberts E, Popay J. Synthesising research evidence. Studying the organisation and delivery of health services. Research methods 2001:188-220.

12. Everitt BS, Skrondal A. The Cambridge Dictionary of Statistics. 4th edn. Cambridge: Cambridge University Press Cambridge, 2010.

13. Vaismoradi $\mathrm{M}$, Turunen $\mathrm{H}$, Bondas $\mathrm{T}$. Content analysis and thematic analysis: Implications for conducting a qualitative descriptive study. Nurs Health Sci 2013;15:398-405.

14. Harrell FE. Regression modeling strategies: with applications to linear models, logistic and ordinal regression, and survival analysis. 2 edn. New York: Springer International Publishing, 2015.

15. Aagaard J, Aagaard A, Buus N. Predictors of frequent visits to a psychiatric emergency room: a large-scale register study combined with a small-scale interview study. Int J Nurs Stud 2014;51:1003-13.

16. Adams RJ, Smith BJ, Ruffin RE. Factors associated with hospital admissions and repeat emergency department visits for adults with asthma. Thorax 2000;55:566-73.

17. Alghanim SA, Alomar BA. Frequent use of emergency departments in Saudi public hospitals: Implications for primary health care services. Asia-Pac J Public Health 2015;27:NP2521-NP30.

18. Alpern ER, Clark AE, Alessandrini EA, et al. Pediatric Emergency Care Applied Research Network (PECARN). Recurrent and highfrequency use of the emergency department by pediatric patients. Acad Emerg Med 2014;21:365-73.

19. Arfken CL, Zeman LL, Yeager L, et al. Case-control study of frequent visitors to an urban psychiatric emergency service. Psychiatr Serv 2004;55:295-301.

20. Bieler G, Paroz S, Faouzi M, et al. Social and medical vulnerability factors of emergency department frequent users in a universal health insurance system. Acad Emerg Med 2012;19:63-8.

21. Billings J, Raven MC. Dispelling an urban legend: frequent emergency department users have substantial burden of disease. Health Aff 2013;32:2099-108.

22. Boyer L, Dassa D, Belzeaux R, et al. Frequent visits to a French psychiatric emergency service: diagnostic variability in psychotic disorders. Psychiatr Serv 2011;62:966-70.

23. Brennan JJ, Chan TC, Hsia RY, et al. Emergency department utilization among frequent users with psychiatric visits. Acad Emerg Med 2014;21:1015-22.

24. Buhumaid R, Riley J, Sattarian M, et al. Characteristics of frequent users of the emergency department with psychiatric conditions. $J$ Health Care Poor Underserved 2015;26:941-50.

25. Cabey WV, MacNeill E, White LN, et al. Frequent pediatric emergency department use in infancy and early childhood. Pediatr Emerg Care 2014;30:710-7.

26. Castner J, Wu YW, Mehrok N, et al. Frequent emergency department utilization and behavioral health diagnoses. Nurs Res 2015;64:3-12.

27. Chambers $\mathrm{C}$, Chiu S, Katic M, et al. High utilizers of emergency health services in a population-based cohort of homeless adults. Am J Public Health 2013;103(S2):S302-10.

28. Chang G, Weiss AP, Orav EJ, et al. Predictors of frequent emergency department use among patients with psychiatric illness. Gen Hosp Psychiatry 2014;36:716-20.

29. Chukmaitov AS, Tang A, Carretta HJ, et al. Characteristics of all, occasional, and frequent emergency department visits due to ambulatory care-sensitive conditions in Florida. J Ambul Care Manage 2012;35:149-58

30. Colligan EM, Pines JM, Colantuoni E, et al. Risk Factors for Persistent Frequent Emergency Department Use in Medicare Beneficiaries. Ann Emerg Med 2016;67:721-9.

31. Das LT, Abramson EL, Stone AE, et al. Predicting frequent emergency department visits among children with asthma using EHR data. Pediatr Pulmonol 2017;52:880-90.

32. Doran KM, Colucci AC, Wall SP, et al. Reasons for emergency department use: do frequent users differ? Am J Manag Care 2014;20:e506-e14.

33. Doran KM, Raven MC, Rosenheck RA. What drives frequent emergency department use in an integrated health system? 
National data from the Veterans Health Administration. Ann Emerg Med 2013;62:151-9.

34. Fernandes AK, Mallmann F, Steinhorst AM, et al. Characteristics of acute asthma patients attended frequently compared with those attended only occasionally in an emergency department. $J$ Asthma 2003;40:683-90.

35. Frost DW, Vembu S, Wang J, et al. Using the Electronic Medical Record to Identify Patients at High Risk for Frequent Emergency Department Visits and High System Costs. Am J Med 2017;130:601.e17-601.e22.

36. Grinspan ZM, Shapiro JS, Abramson EL, et al. Predicting frequent ED use by people with epilepsy with health information exchange data. Neurology 2015;85:1031-8.

37. Hasegawa $\mathrm{K}$, Tsugawa $\mathrm{Y}$, Brown DF, et al. A population-based study of adults who frequently visit the emergency department for acute asthma. California and Florida, 2009-2010. Ann Am Thorac Soc 2014:11:158-66.

38. Huang JA, Tsai WC, Chen YC, et al. Factors associated with frequent use of emergency services in a medical center. $J$ Formos Med Assoc 2003;102:222-8

39. Hudon C, Sanche S, Haggerty JL. Personal Characteristics and Experience of Primary Care Predicting Frequent Use of Emergency Department: A Prospective Cohort Study. PLoS One 2016;11:e0157489.

40. Kerr T, Wood E, Grafstein E, et al. High rates of primary care and emergency department use among injection drug users in Vancouver. J Public Health 2005;27:62-6.

41. Kirby SE, Dennis SM, Jayasinghe UW, et al. Patient related factors in frequent readmissions: the influence of condition, access to services and patient choice. BMC Health Serv Res 2010;10:216.

42. Kirby SE, Dennis SM, Jayasinghe UW, et al. Frequent emergency attenders: is there a better way? Aust Health Rev 2011;35:462-7.

43. Ko M, Lee $\mathrm{Y}$, Chen $\mathrm{C}$, et al. Prevalence of and Predictors for Frequent Utilization of Emergency Department: A Population-Based Study. Medicine 2015;94:e1205.

44. Ledoux Y, Minner P. Occasional and frequent repeaters in a psychiatric emergency room. Soc Psychiatry Psychiatr Epidemiol 2006;41:115-21.

45. Legramante JM, Morciano L, Lucaroni F, et al. Frequent use of emergency departments by the elderly population when continuing care is not well established. PLoS One 2016;11:e0165939.

46. Leporatti L, Ameri M, Trinchero C, et al. Targeting frequent users of emergency departments: Prominent risk factors and policy implications. Health Policy 2016;120:462-70.

47. Lim SF, Wah W, Pasupathi Y, et al. Frequent attenders to the ED: patients who present with repeated asthma exacerbations. Am J Emerg Med 2014;32:895-9.

48. Limsrivilai J, Stidham RW, Govani SM, et al. Factors That Predict High Health Care Utilization and Costs for Patients With Inflammatory Bowel Diseases. Clin Gastroenterol Hepatol 2017:15:385-92.

49. Liu SW, Nagurney JT, Chang Y, et al. Frequent ED users: are most visits for mental health, alcohol, and drug-related complaints? Am J Emerg Med 2013;31:1512-5.

50. Mandelberg JH, Kuhn RE, Kohn MA. Epidemiologic analysis of an urban, public emergency department's frequent users. Acad Emerg Med 2000;7:637-46.

51. Mann EG, Johnson A, VanDenKerkhof EG. Frequency and characteristics of healthcare visits associated with chronic pain: results from a population-based Canadian study. Can J Anaesth 2016:63:411-41.

52. McMahon CG, Power Foley M, Robinson D, et al. High prevalence of frequent attendance in the over 65s. Eur J Emerg Med 2018;25:1.

53. Milani SA, Crooke H, Cottler LB, et al. Sex differences in frequent ED use among those with multimorbid chronic diseases. Am J Emerg Med 2016;34:2127-31.

54. Mueller EL, Hall M, Carroll AE, et al. Frequent Emergency Department Utilizers Among Children with Cancer. Pediatr Blood Cancer 2016;63:859-64.

55. Nambiar D, Stoové M, Dietze P. Frequent emergency department presentations among people who inject drugs: A record linkage study. Int J Drug Policy 2017;44:115-20.

56. Neufeld E, Viau KA, Hirdes JP, et al. Predictors of frequent emergency department visits among rural older adults in Ontario using the Resident Assessment Instrument-Home Care. Aust $J$ Rural Health 2016;24:115-22.

57. Norman C, Mello M, Choi B. Identifying Frequent Users of an Urban Emergency Medical Service Using Descriptive Statistics and Regression Analyses. West J Emerg Med 2016;17:39-45.
58. Palmer E, Leblanc-Duchin D, Murray J, et al. Emergency department use: is frequent use associated with a lack of primary care provider? Can Fam Physician 2014;60:e223-e9.

59. Panopalis P, Gillis JZ, Yazdany J, et al. Frequent use of the emergency department among persons with systemic lupus erythematosus. Arthritis Care Res 2010;62:401-8.

60. Paul P, Heng BH, Seow E, et al. Predictors of frequent attenders of emergency department at an acute general hospital in Singapore. Emerg Med J 2010;27:843-8.

61. Pereira M, Singh V, Hon CP, Greg McKelvey T, Sushmita S, De Cock M, et al. eds. Predicting future frequent users of emergency departments in California state2016: Association for Computing Machinery, Inc.

62. Pines JM, Buford K. Predictors of frequent emergency department utilization in Southeastern Pennsylvania. J Asthma 2006;43:219-23.

63. Quilty S, Shannon G, Yao A, et al. Factors contributing to frequent attendance to the emergency department of a remote Northern Territory hospital. Med J Aust 2016;204:111-7.

64. Samuels-Kalow ME, Bryan MW, Shaw KN, et al. Low-Acuity Utilization of the Pediatric Emergency Department. Acad Pediatr 2017;17:256-60.

65. Schmoll S, Boyer L, Henry JM, et al. [Frequent visitors to psychiatric emergency service: Demographical and clinical analysis]. Encephale 2015;41:123-9.

66. Soler JJ, Sánchez L, Román P, et al. Risk factors of emergency care and admissions in COPD patients with high consumption of health resources. Respir Med 2004;98:318-29.

67. Sun BC, Burstin HR, Brennan TA. Predictors and outcomes of frequent emergency department users. Acad Emerg Med 2003;10:320-8

68. Tangherlini N, Pletcher MJ, Covec MA, et al. Frequent use of emergency medical services by the elderly: a case-control study using paramedic records. Prehosp Disaster Med 2010;25:258-64.

69. Thakarar K, Morgan JR, Gaeta JM, et al. Predictors of Frequent Emergency Room Visits among a Homeless Population. PLoS One 2015;10:e0124552.

70. Vandyk AD, VanDenKerkhof EG, Graham ID, et al. Profiling frequent presenters to the emergency department for mental health complaints: socio-demographic, clinical, and service use characteristics. Arch Psychiatr Nurs 2014;28:420-5.

71. Vinton DT, Capp R, Rooks SP, et al. Frequent users of US emergency departments: characteristics and opportunities for intervention. Emerg Med J 2014;31:526-32.

72. Vu F, Daeppen JB, Hugli O, et al. Screening of mental health and substance users in frequent users of a general Swiss emergency department. BMC Emerg Med 2015;15:27.

73. Watase H, Hagiwara Y, Chiba T, et al. Japanese Emergency Medicine Network Investigators. Multicentre observational study of adults with asthma exacerbations: who are the frequent users of the emergency department in Japan? BMJ Open 2015;5:e007435.

74. Woo JH, Grinspan Z, Shapiro J, et al. Frequent Users of Hospital Emergency Departments in Korea Characterized by Claims Data from the National Health Insurance: A Cross Sectional Study. PLOS One 2016;11:e0147450.

75. Wu J, Grannis SJ, Xu H, et al. A practical method for predicting frequent use of emergency department care using routinely available electronic registration data. BMC Emerg Med 2016;16:12.

76. Hasegawa K, Tsugawa Y, Tsai CL, et al. Frequent utilization of the emergency department for acute exacerbation of chronic obstructive pulmonary disease. Respir Res 2014;15:40.

77. Freitag FG, Kozma CM, Slaton T, et al. Characterization and prediction of emergency department use in chronic daily headache patients. Headache 2005;45:891-8.

78. Friedman BW, Serrano D, Reed M, et al. Use of the emergency department for severe headache. A population-based study. Headache 2009;49:21-30.

79. O'Toole TP, Pollini R, Gray P, et al. Factors identifying highfrequency and low-frequency health service utilization among substance-using adults. J Subst Abuse Treat 2007:33:51-9.

80. Pasic J, Russo J, Roy-Byrne P. High utilizers of psychiatric emergency services. Psychiatr Serv 2005;56:678-84.

81. Rask KJ, Williams MV, McNagny SE, et al. Ambulatory health care use by patients in a public hospital emergency department. J Gen Intern Med 1998:13:614-20.

82. Blonigen DM, Macia KS, Bi X, et al. Factors associated with emergency department useamong veteran psychiatric patients. Psychiatr Q 2017;88:721-32.

83. Batra P, Fridman M, Leng M, et al. Emergency Department Care in the Postpartum Period: California Births, 2009-2011. Obstet Gynecol 2017;130:1073-81. 
84. Burner E, Ruiz A, Sanchez A, et al. 155 Insulin Use Predicts High Emergency Department Utilization Among Patients With Poorly Controlled Diabetes. Ann Emerg Med 2018;72:S65-S.

85. Flood C, Sheehan K, Crandall M. Predictors of Emergency Department Utilization Among Children in Vulnerable Families. Pediatr Emerg Care 2017;33:765-9.

86. Kanzaria HK, Niedzwiecki MJ, Montoy JC, et al. Persistent Frequent Emergency Department Use: Core Group Exhibits Extreme Levels Of Use For More Than A Decade. Health Aff 2017;36:1720-8.

87. Naseer M, Dahlberg L, Fagerström C. Health related quality of life and emergency department visits in adults of age $\geq 66$ years: a prospective cohort study. Health Qual Life Outcomes 2018;16:144.

88. Samuels-Kalow M, Peltz A, Rodean J, et al. Predicting LowResource-Intensity Emergency Department Visits in Children. Acad Pediatr 2018;18:297-304.

89. Weidner TK, Kidwell JT, Etzioni DA, et al. Factors Associated with Emergency Department Utilization and Admission in Patients with Colorectal Cancer. J Gastrointest Surg 2018;22:913-20.

90. Zook HG, Kharbanda AB, Puumala SE, et al. Emergency Department Utilization by Native American Children. Pediatr Emerg Care 2018;34:802-9

91. Ahn E, Kim J, Rahman K, et al. Development of a risk predictive scoring system to identify patients at risk of representation to emergency department: a retrospective population-based analysis in Australia. BMJ Open 2018;8:e021323.

92. Andrews CM, Westlake M, Wooten N. Availability of Outpatient Addiction Treatment and Use of Emergency Department Services Among Medicaid Enrollees. Psychiatr Serv 2018;69:729-32.

93. Gruneir A, Cigsar C, Wang X, et al. Repeat emergency department visits by nursing home residents: a cohort study using health administrative data. BMC Geriatr 2018;18:157.

94. Lee J, Lin J, Suter LG, et al. Persistently Frequent Emergency Department Utilization among Persons with Systemic Lupus Erythematosus. Arthritis Care Res 2018 (Epub 2018/10/09).

95. Mann EG, Johnson A, Gilron I, et al. Pain Management Strategies and Health Care Use in Community-Dwelling Individuals Living with Chronic Pain. Pain Med 2017;18:2267-79.

96. Colligan EM, Pines JM, Colantuoni E, et al. Factors Associated With Frequent Emergency Department Use in the Medicare Population. Med Care Res Rev 2017;74:311-27.

97. Cunningham A, Mautner D, Ku B, et al. Frequent emergency department visitors are frequent primary care visitors and report unmet primary care needs. J Eval Clin Pract 2017;23:567-73.

98. Kidane B, Jacob B, Gupta V, et al. Medium and long-term emergency department utilization after oesophagectomy: a population-based analysis. Eur J Cardiothorac Surg 2018;54:683-8.

99. Schlichting LE, Rogers ML, Gjelsvik A, et al. Pediatric Emergency Department Utilization and Reliance by Insurance Coverage in the United States. Acad Emerg Med 2017;24:1483-90.

100. Supat B, Brennan JJ, Vilke GM, et al. Characterizing pediatric high frequency users of California emergency departments. Am J Emerg Med 2018.

101. Peltz A, Samuels-Kalow ME, Rodean J, et al. Characteristics of Children Enrolled in Medicaid With High-Frequency Emergency Department Use. Pediatrics 2017;140:e20170962.

102. Hasegawa K, Tsugawa $Y$, Camargo CA, et al. Frequent utilization of the emergency department for acute heart failure syndrome: a population-based study. Circ Cardiovasc Qual Outcomes 2014;7:735-42

103. Huynh C, Ferland F, Blanchette-Martin N, et al. Factors Influencing the Frequency of Emergency Department Utilization by Individuals with Substance Use Disorders. Psychiatr Q 2016;87:713-28.

104. Lin WC, Bharel M, Zhang J, et al. Frequent Emergency Department Visits and Hospitalizations Among Homeless People With Medicaid: Implications for Medicaid Expansion. Am J Public Health 2015;105:S716-22

105. Beck A, Sanchez-Walker E, Evans LJ, et al. Characteristics of people who rapidly and frequently reattend the emergency department for mental health needs. Eur J Emerg Med 2016;23:351-5.

106. Nambiar D, Spelman T, Stoové M, et al. Are People Who Inject Drugs Frequent Users of Emergency Department Services? A Cohort Study (2008-2013). Subst Use Misuse 2018;53:457-65.

107. Christensen EW, Kharbanda AB, Velden HV, et al. Predicting Frequent Emergency Department Use by Pediatric Medicaid Patients. Popul Health Manag 2017;20:208-15.

108. Hardie TL, Polek C, Wheeler E, et al. Characterising emergency department high-frequency users in a rural hospital. Emerg Med J 2015;32:21-5

109. Meyer JP, Qiu J, Chen NE, et al. Frequent emergency department use among released prisoners with human immunodeficiency virus: characterization including a novel multimorbidity index. Acad Emerg Med 2013;20:79-88.

110. Milbrett P, Halm M. Characteristics and predictors of frequent utilization of emergency services. J Emerg Nurs 2009;35:191-8.

111. Sacamano P, Krawczyk N, Latkin C. Emergency Department Visits in a Cohort of Persons with Substance Use: Incorporating the Role of Social Networks. Subst Use Misuse 2018;53:2265-9.

112. Blair M, Poots AJ, Lim V, et al. Preschool children who are frequent attenders in emergency departments: an observational study of associated demographics and clinical characteristics. Arch Dis Child 2018;103.

113. Genell Andrén K, Rosenqvist U. Heavy users of an emergency department--a two year follow-up study. Soc Sci Med 1987;25:825-31.

114. Girts TK, Crawford AG, Goldfarb NI, et al. Predicting High Utilization of Emergency Department Services Among Patients with a Diagnosis of Psychosis in a Medicaid Managed Care Organization. Disease Management 2002;5:189-96.

115. Rauch J, Hüsers J, Babitsch B, et al. Understanding the Characteristics of Frequent Users of Emergency Departments: What Role Do Medical Conditions Play? Stud Health Technol Inform 2018;253:175-9.

116. Wong TH, Lau ZY, Ong WS, et al. Cancer patients as frequent attenders in emergency departments: A national cohort study. Cancer Med 2018;7:4434-46.

117. Neuman MI, Alpern ER, Hall M, et al. Characteristics of recurrent utilization in pediatric emergency departments. Pediatrics 2014;134:e1025-e31.

118. Ngamini-Ngui A, Fleury MJ, Moisan J, et al. High users of emergency departments in Quebec among patients with both schizophrenia and a substance use disorder. Psychiatr Serv 2014:65:1389-91.

119. Samuels-Kalow ME, Faridi MK, Espinola JA, et al. Comparing Statewide and Single-center Data to Predict High-frequency Emergency Department Utilization Among Patients With Asthma Exacerbation. Acad Emerg Med 2018;25:657-67.

120. Altman DG. Practical statistics for medical research. London: CRC press, 1990

121. Moe J, Bailey AL, Oland R, et al. Defining, quantifying, and characterizing adult frequent users of a suburban Canadian emergency department. CJEM 2013;15:214-26.

122. Wajnberg A, Hwang U, Torres L, et al. Characteristics of frequent geriatric users of an urban emergency department. J Emerg Med 2012;43:376-81.

123. Street M, Berry D, Considine J. Frequent use of emergency departments by older people: a comparative cohort study of characteristics and outcomes. Int J Qual Health Care 2018;30:624-9.

124. Birmingham LE, Cochran T, Frey JA, et al. Emergency department use and barriers to wellness: a survey of emergency department frequent users. BMC Emerg Med 2017;17:16

125. Kim JJ, Kwok ESH, Cook OG, et al. Characterizing Highly Frequent Users of a Large Canadian Urban Emergency Department. West $J$ Emerg Med 2018;19:926-33.

126. Klein LR, Martel ML, Driver BE, et al. Emergency Department Frequent Users for Acute Alcohol Intoxication. West J Emerg Med 2018;19:398-402.

127. Kononenko I. Machine learning for medical diagnosis: history, state of the art and perspective. Artif Intell Med 2001;23:89-109.

128. Hu X, Barnes S, Bjarnadóttir M, et al. Intelligent selection of frequent emergency department patients for case management: A machine learning framework based on claims data. IISE Trans Healthc Syst Eng 2017;7:130-43.

129. Liao S-H, Chu P-H, Hsiao P-Y. Data mining techniques and applications - A decade review from 2000 to 2011. Expert Syst Appl 2012;39:11303-11.

130. Wang S, Summers RM. Machine learning and radiology. Med Image Anal 2012;16:933-51.

131. Kourou K, Exarchos TP, Exarchos KP, et al. Machine learning applications in cancer prognosis and prediction. Comput Struct Biotechnol J 2015;13:8-17

132. Ramos-Pollán R, Guevara-López MA, Suárez-Ortega C, et al. Discovering mammography-based machine learning classifiers for breast cancer diagnosis. J Med Syst 2012;36:2259-69.

133. Murdoch TB, Detsky AS. The inevitable application of big data to health care. JAMA 2013;309:1351-2.

134. Churpek MM, Yuen TC, Winslow C, et al. Multicenter Comparison of Machine Learning Methods and Conventional Regression for Predicting Clinical Deterioration on the Wards. Crit Care Med 2016;44:368-74. 
135. Hastie T, Tibshirani R, Friedman J. The Elements of Statistical Learning. New York: Springer, 2009.

136. Sanchez-Pinto LN, Luo Y, Churpek MM. Big Data and Data Science in Critical Care. Chest 2018;154:1239-48.

137. Johnson KW, Torres Soto J, Glicksberg BS, et al. Artificial Intelligence in Cardiology. J Am Coll Cardiol 2018;71:2668-79.

138. Taylor RA, Pare JR, Venkatesh AK, et al. Prediction of In-hospital Mortality in Emergency Department Patients With Sepsis: A Local Big Data-Driven, Machine Learning Approach. Acad Emerg Med 2016;23:269-78.

139. Jolliffe IT. Principal Component Analysis and Factor Analysis. Principal component analysis: Springer, 1986:115-28.

140. Burgel PR, Paillasseur JL, Caillaud D, et al. Initiatives BPCO Scientific Committee. Clinical COPD phenotypes: a novel approach using principal component and cluster analyses. Eur Respir J 2010;36:531-9.
141. Gordon DB, Polomano RC, Pellino TA, et al. Revised American Pain Society Patient Outcome Questionnaire (APS-POQ-R) for quality improvement of pain management in hospitalized adults: preliminary psychometric evaluation. J Pain 2010;11:1172-86.

142. Gasquet I, Villeminot S, Estaquio C, et al. Construction of a questionnaire measuring outpatients' opinion of quality of hospital consultation departments. Health Qual Life Outcomes 2004;2:43.

143. Koenker R. Quantile regression: Cambridge university press, 2005.

144. Ding R, McCarthy ML, Desmond JS, et al. Characterizing waiting room time, treatment time, and boarding time in the emergency department using quantile regression. Acad Emerg Med 2010;17:813-23.

145. Bottai M, Cai B, McKeown RE. Logistic quantile regression for bounded outcomes. Stat Med 2010;29:309-17. 